\title{
VIII. Examination of a native sulphuret of bismuth
}

\section{Mr. R. Warrington}

To cite this article: Mr. R. Warrington (1831) VIII. Examination of a native sulphuret of bismuth , Philosophical Magazine Series 2, 9:49, 29-31, DOI: 10.1080/14786443108647526

To link to this article: http://dx.doi.org/10.1080/14786443108647526

册 Published online: 01 Jun 2009.

Submit your article to this journal 준

Џll Article views: 2

Q View related articles $₫$ 
Admiral) shall consider expedient. And when our said astronomer and the Council of our Royal Society and of the Astronomical Society shall have been supplied with as many copies as they may desire, to distribute for the benefit of science, the remainder shall be sold at such price as the Lord High Admiral shall fix. And our further will and pleasure is, that you do meet annually at our said Observatory on the first Saturday in the month of June, and at such other times as may seem expedient to our Lord High Admiral (or the Commissioners for executing the office of Lord High Admiral), and that at such meeting the President of our Royal Society shall take the chair, or in his absence the President of the Astronomical Society; or in the absence of both the said Presidents, that the Fellows and Members present (of whom seven shall form a quorum) shall elect a chairman for the time being among themselves: and that at every such meeting the chairman shall be empowered to call in and employ one of the assistants in our said Observatory to act as secretary for the time being. And our further will and pleasure is, that as often as any vacancies occur by death or resignation, the same shall be filled up by the President of the Society, in whose list such vacancy may have happened. And our further will and pleasure is, that any President of our said Royal Society, or any President of the Astronomical Society, who may have become a Visitor to our Royal Observatory, by virtue of his office, shall during our pleasure continue to be a Visitor notwithstanding that he may have vacated the office of President of such Society. And for so doing, this shall be your warrant. And so we bid you farewell.-Given at our Court at Saint James's, \&c. \&c. \&c.

"To our trusty and well-beloved the President of our Royal Society for the time being, the President of the Astronomical Society for the time being, and the other persons hereby appointed Visitors of our Royal Observatory at Greenwich.

By His Majesty's command, "Robert Peel."

VIII. Examination of a Native Sulphuret of Bismuth. By Mr. R. WaRRING'OON*

THE mineral which forms the subject of the present paper, 1 is found in the western parts of Cornwall; it occupies the cavities and fissures of a porous mass of yellow copper pyrites and silica, in the form of striated needles and bands.

* Communicated by the Author. 
It has exteriorly an iron-gray colour, sometimes with a bismuthic tinge, and in its cleavage surface possesses a lustre approaching that of polished steel. Its specific gravity is 5.85 , and its hardness $=2 \cdot 7$. When heated before the blowpipe on charcoal it inflames, and by increasing the heat for some time, appears to be entirely volatilized, with the exception of a minute globule of brown scoriaceous matter.

On examination it was found to contain bismuth, sulphur, copper, iron, and siliceous matter. The first analysis was performed by acting upon the mineral, reduced to a very fine powder, with nitro-muriatic acid, until the whole of the sulphur was acidified; this was conducted in a small stoppered retort, to which a receiver was attached, in order to collect any small quantity of sulphur that might be carried over mechanically during the digestion. The solution thus obtained was diluted with water, and filtered to separate the silica; a solution of nitrate of baryta was employed for the precipitation of the sulphuric acid, and the sulphate of baryta (and also the silica) washed at intervals with warm dilute nitric acid, to remove any small quantity of bismuth which might fall by the gradual dilutions. - After the separation of the excess of baryta, ammonia was added in slight excess, which threw down the oxides of bismuth and iron, and held the oxide of copper in solution; by evaporation to dryness and the addition of potassa this oxide was obtained.

The mixed oxides were then acted upon by dilute muriatic acid, added in small quantity; the oxide of iron was thus completely removed, and the dichloride of bismuth which remained, after being digested in a weak solution of potassa, was collected as an oxide: the iron was again precipitated from its muriatic solution by ammonia.

Although this analysis was conducted with the greatest care, and repeated in order to avoid ambiguity, yet the results in both cases exceeded the weight of the mineral employed. Upon heating the oxide of bismuth obtained in the second analysis, before weighing (and which was performed in a small tube of green glass sealed at one of its extremities), it was observed that a small quantity of white opaque vapour arose and appeared to be condensed upon the upper part of the tube, and on adding distilled water to it, a precipitate of dichloride of bismuth was instantly formed, proving it to have been sublimed chloride of that metal. The oxide itself was next examined; by dissolving it in pure nitric acid, and testing the solution with nitrate of silver, a small quantity of chloride of silver was thrown down.

Having ascertained these facts, a solution of muriate of bismuth 
bismuth was prepared, and the three following experiments tried with it:- -one quantity was precipitated by potassa in great excess, another by ammonia, and these were digested at a boiling heat for abont six hours; the third portion was added gradually to a large quantity of very hot solution of potassa; and the whole three collected and well washed, dissolved in nitric acid and tested as before; muriatic acid was however detected in each. It was evident from these results, that muriatic acid could not be employed in the analysis, or that, if employed, it must be separated before the precipitation of the oxide of bismuth. $6.88 \mathrm{grs}$. of the mineral were digested in nitric acid as long as any sulphur remained undissolved; it was then filtered, and gave $\cdot 345 \mathrm{gr}$. silica. The sulphuric acid was next separated by a solution of nitrate of baryta added as long as any precipitate was occasioned, and the sulphate of baryta, after heating to redness, weighed $9 \cdot 654$ grs. After the excess of baryta had been carefully removed, ammonia added in excess threw down the oxides of bismuth and iron as before, and held the oxide of copper, which was obtained in the manner before stated, and equalled 306 of a grain. The weight of the mixed oxides was 5 594 grs., which were then dissolved in muriatic acid, and a current of sulphuretted hydrogen passed through the solution, and the whole thrown upon a filter: the clear solution which passed through was boiled for some time, and after the addition of a little nitric acid to bring the iron to the state of peroxide, ammonia was added, and the oxide collected weighed $\cdot 344$ gr.; deducting this from the weight of the mixed oxides, leaves 5.25 grs. as the quantity of oxide of bismuth; the results are, therefore,

$$
\begin{aligned}
& \text { Oxide of bismuth...... } 5 \cdot 25=4 \cdot 718 \text { bismuth. } \\
& \text { Sulphate of baryta .... 9.654 }=1 \cdot 309 \text { sulphur. } \\
& \text { Peroxide of iron...... } 344=.241 \text { iron. } \\
& \text { Peroxide of copper... } .306=.245 \text { copper. } \\
& .34 .5 \text { silica. } \\
& 6 \cdot 858 \\
& .022 \text { loss. } \\
& 6 \cdot 880
\end{aligned}
$$

Or, we may consider the mineral to be constituted of $5 \cdot 7815$ grs. sulphuret of bismuth, being in the proportion of 1 atom bismuth +1 atom sulphur, and that the iron, copper, and silica are merely parts of the matrix which cannot be separated mechanically from the pure mineral. 